\title{
Assessment of Ceragenins in Prevention of Damage to Voice Prostheses Caused by Candida Biofilm Formation
}

\author{
Jakub Spałek 1,2,3(D), Tamara Daniluk ${ }^{3}$, Adrian Godlewski ${ }^{4}{ }^{\circledR}$, Piotr Deptuła ${ }^{3}$, Urszula Wnorowska ${ }^{3}$,

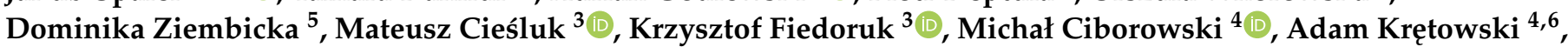 \\ Stanisław Góźdź ${ }^{1}$, Bonita Durnaś ${ }^{1}$, Paul B. Savage ${ }^{7}$, Sławomir Okła ${ }^{1,2}$ and Robert Bucki ${ }^{3, *} \mathbb{C}$
}

1 Institute of Medical Science, Collegium Medicum, Jan Kochanowski University of Kielce, IX Wieków Kielc 19A, 25-317 Kielce, Poland; jspalek@ujk.edu.pl (J.S.); Stanislaw.Gozdz@onkol.kielce.pl (S.G.); Bonita.Durnas@onkol.kielce.pl (B.D.); slawomir.okla@gmail.com (S.O.)

2 Department of Otolaryngology, Head and Neck Surgery, Holy-Cross Cancer Center, Artwińskiego 3, 25-734 Kielce, Poland

3 Department of Medical Microbiology and Nanobiomedical Engineering, Medical University of Bialystok, Mickiewicza 2C, 15-222 Bialystok, Poland; tamara.daniluk@umb.edu.pl (T.D.); piotr.deptula@umb.edu.pl (P.D.); urszula.wnorowska@umb.edu.pl (U.W.); mticv1@gmail.com (M.C.); krzysztof.fiedoruk@umb.edu.pl (K.F.)

4 Metabolomics Laboratory, Clinical Research Centre, Medical University of Białystok, 15-089 Białystok, Poland; adrian.godlewski@umb.edu.pl (A.G.); michal.ciborowski@umb.edu.pl (M.C.); adam.kretowski@umb.edu.pl (A.K.)

check for updates

Citation: Spałek, J.; Daniluk, T.; Godlewski, A.; Deptuła, P.; Wnorowska, U.; Ziembicka, D.; Cieśluk, M.; Fiedoruk, K.; Ciborowski, M.; Krẹtowski, A.; et al. Assessment of Ceragenins in Prevention of Damage to Voice Prostheses Caused by Candida Biofilm Formation. Pathogens 2021, 10, 1371. https://doi.org/10.3390/ pathogens10111371

Academic Editor: Lawrence S. Young

Received: 22 September 2021

Accepted: 20 October 2021

Published: 23 October 2021

Publisher's Note: MDPI stays neutral with regard to jurisdictional claims in published maps and institutional affiliations.

Copyright: (C) 2021 by the authors Licensee MDPI, Basel, Switzerland. This article is an open access article distributed under the terms and conditions of the Creative Commons Attribution (CC BY) license (https:// creativecommons.org/licenses/by/ $4.0 /)$.
5 Department of Public Health, Medical University of Białystok, 15-089 Białystok, Poland; dominika.ziembicka@umb.edu.pl

6 Department of Endocrinology, Diabetology and Internal Medicine, Medical University of Białystok, 15-089 Białystok, Poland

7 Department of Chemistry and Biochemistry, Brigham Young University, Provo, UT 84602, USA; pbsavage@chem.byu.edu

* Correspondence: buckirobert@gmail.com; Tel.: +48-85-748-54-83

Abstract: This study aimed to investigate the potential application of ceragenins (CSAs) as new candidacidal agents to prevent biofilm formation on voice prostheses (VPs). The deterioration of the silicone material of VPs is caused by biofilm growth on the device which leads to frequent replacement procedures and sometimes serious complications. A significant proportion of these failures is caused by Candida species. We found that CSAs have significant candidacidal activities in vitro (MIC; MFC; $\mathrm{MBIC}$ ), and they effectively eradicate species of yeast responsible for VP failure. Additionally, in our in vitro experimental setting, when different Candida species were subjected to CSA-13 and CSA-131 during 25 passages, no tested Candida strain showed the significant development of resistance. Using liquid chromatography-mass spectrometry (LC-MS), we found that VP immersion in an ethanol solution containing CSA-131 results in silicon impregnation with CSA-131 molecules, and in vitro testing revealed that fungal biofilm formation on such VP surfaces was inhibited by embedded ceragenins. Future in vivo studies will validate the use of ceragenin-coated VP for improvement in the life quality and safety of patients after a total laryngectomy.

Keywords: ceragenins; silicone; impregnation; voice prostheses; biofilm; Candida spp.

\section{Introduction}

A tracheoesophageal puncture with voice prosthesis (VP) implantation is the most effective method of voice rehabilitation among patients after a total laryngectomy (TL) [1] The principle of this method is to restore the connection between the airways (trachea) and upper parts of the gastrointestinal tract (esophagus, pharynx, oral cavity) through the creation of a tracheoesophageal fistula with a one-way valve device inside. This allows airflow from the trachea to the esophagus and prevents esophageal content from leaking into the airways. Currently, Blom-Singer and Provox VP models are the most commonly 
used [2]. Since 1980, this type of VP has been based on medical-grade silicon material [3]. One of the most significant disadvantages of silicone polymer-based VPs and other medical devices is their susceptibility to colonization by fungi and bacteria [4-6]. Candida spp. colonization and biofilm formation substantially impacts VP durability. In our previous studies, we found that the four most common Candida species that correlated with the characteristic structural damage of the VP material (SEM, AFM) [7] were Candida krusei, Candida albicans, Candida glabrata, and Candida tropicalis. These observations have been confirmed by the studies of other authors [6-8].

It has been reported that it is the biofilms of the medical devices that are mostly responsible for serious infections, for example, $90 \%$ of catheter-related infections need hospitalization. Up to $70 \%$ of Candida spp. bloodstream infections are associated with central venous catheters [2]. However, there is no study yet that reports the correlation observed between microbial biofilm presence on voice prostheses and local infections, but there is a potential threat that colonized devices could be the origin of systemic infections in specific situations. On the other hand, the process of biofilm growth is the main reason for VP damage and deformation, which leads to its dysfunction. Leakage of the esophageal content by the tracheoesophageal fistula is the most common and potentially life-threatening dysfunction. Laccourreye et al. report that the cause for replacement was leakage through the prosthesis valve ( $33 \%$ of cases) and leakage around the prosthesis ( $27 \%$ of cases). It may lead to aspiration pneumonia and requires urgent replacement. Increased airflow resistance of the prosthesis valve results in problems with phonation and leads to replacement ( $40 \%$ of cases) [9]. The average VP lifespan is variable within the range of between approximately 4 and 8 months $[7,10]$. The lifespan of the Provox VP may be longer in some single extremal cases [11]. There have been some attempts to manage the short effective lifespan of VP. Provox has developed a new type of valve mechanism in their devices, the Provox ActiValve, based on Provox 2. It is made of the same medical-grade silicone, but the valve seat and the valve flap are made of fluoroplastic, using magnets available in three different strengths to support valve closure. This modification has significantly elongated the VP lifespan, but the cost of the devices is high, so it is not commonly used. Moreover, the Provox ActiValve was designed for patients with frequent central-type leakage. There is no improvement in patients with the VP lateral leakage throughout the fistula [10]. There have also been other approaches to improve VP durability by reducing the development of biofilm. The application of nystatin, antimicrobial agents, oral wash, or VP cleaning by a special brush have advantages and disadvantages; however, these have no clinically satisfactory results $[12,13]$, potentially because of insufficient candidacidal activity of the cleaning products.

Ceragenins (CSAs) are amphiphilic derivatives of bile acids with covalently attached amines that mimic the amphipathic properties of endogenous antimicrobial peptides (AMP) expressed in many organisms including bacteria, fungi, plants, insects, worms, and mammals. The mechanism of their antimicrobial action involves membrane binding and insertion that induces morphological changes in the structure of the pathogen's membrane leading to its destruction and cell death. Previous studies report antimicrobial activities of different ceragenins (e.g., CSA-13, CSA-131, CSA-192) against Gram-negative and Grampositive bacteria, Candida species, parasites, and some viruses [14-21]. Ceragenins have better antifungal and antibacterial properties against monomicrobial or fungal-bacterial multispecies biofilms than other commonly used antimicrobials [22]. They also inhibit the attachment and the formation of Candida biofilms [23], and this effect can be potentiated by nanosystems containing ceragenins and metallic nanoparticles [21]. In this study, we describe the activity of CSAs against clinical isolates of Candida strains collected from VPs of patients after a total laryngectomy. Additionally, we also tested whether CSAs induced resistance in Candida over 25 passages. Overall, our observation provides strong support for the development of this group of molecules for the prevention of VP destruction associated with Candida colonization and biofilm development. 


\section{Results}

2.1. Ceragenin CSA-131 Displays the Strongest Candidacidal Activity against Tested Candida Strains from Group of Tested Antimicrobial Agents

For the first step of the study, we assessed the fungicidal activity and inhibition of biofilm formation of commonly used or currently developed antifungal agents including amphotericin B, fluconazole, and omiganan against clinical isolates of four selected Candida species. We also assessed the fungicidal activity of cathelicidin LL-37 and synthetic nonpeptide analogs: CSA-13, CSA-131, CSA-138, and CSA-44. The results were dependent on Candida species, but overall, CSA-131 was the most effective antifungal molecule. The results of the antimicrobial activities of tested agents for the studied clinical isolates $(C$. albicans, C. krusei, C. tropicalis, C. glabrata) are presented in Table 1. The strongest biological activity was observed against the strains of C. glabrata and C. krusei; $\mathrm{MIC}_{90} / \mathrm{MFC}_{90}$ were measured at $0.5 \mu \mathrm{g} / \mathrm{mL}$ of CSA-131. $\mathrm{MIC}_{90} / \mathrm{MFC}_{90}$ of amphotericin B for tested strains was recorded at a concentration of $4 \mu \mathrm{g} / \mathrm{mL}$, while the activity of cathelicidin LL-37 was significantly lower $\left(\mathrm{MIC}_{90} / \mathrm{MFC}_{90}=512 \mu \mathrm{g} / \mathrm{mL}\right)$. The minimum biofilm inhibitory concentration $\left(\mathrm{MBIC}_{90}\right)$ of CSA-131 was significantly lower than other agents with each clinical strain. The strongest antifungal activity was observed against C. krusei and C. tropicalis $(1 \mu \mathrm{g} / \mathrm{mL})$. Notably, $\mathrm{MBIC}_{90}$ for amphotericin B was the lowest among those strains as well, at a concentration of $4 \mu \mathrm{g} / \mathrm{mL}$. It is noteworthy that the fungicidal activity of fluconazole and LL-37 were the lowest for each of the Candida strains; $\mathrm{MIC}_{90} / \mathrm{MFC}_{90} / \mathrm{MBIC}_{90}$ values reached $512 \mu \mathrm{g} / \mathrm{mL}$. On the other hand, ceragenins were the most effective among all tested agents, and CSA-131 was the most effective among all the tested ceragenins. The MIC distribution of all tested ceragenins in different Candida species is presented in Figure 1.

\subsection{Prolongated Incubation of Candida with Ceragenins Did Not Result in Development of Candida Resistance}

Candida spp. were tested in vitro for the potential development of drug resistance against ceragenins CSA-131 and CSA-13. For CSA-13, a gradual increase in MIC was observed between 4 and 6 passages with each different clinical isolate of Candida. However, this increase for 4 out of 5 tested strains was not above the 2-fold dilution factor, which is considered as within the range of possible error for MIC methods. In the case of CSA-131, we did not observe any increase in MICs throughout 25 passages for three isolates. With one isolate of $C$. tropicalis and one isolate of $C$. albicans, the CSA-131 MIC changed from 1 to $2 \mu \mathrm{g} / \mathrm{mL}$ after 7 passages (Figure 2).

\subsection{The Impregnation of VP in an Ethanolic Solution of Ceragenin Prevents the Development of Candida Biofilm on Their Surface}

Silicones are known to swell in the presence of alcohols, and this process may be used to incorporate actives into the silicone. To assess if ceragenin dissolved in isopropyl alcohol might be used to impregnate silicon, we monitored the concentration of CSA-131 in a solution incubated with a silicone VP. We observed a decrease in CSA-131 concentration after the incubation of VPs indicating a preferential interaction of the ceragenin with silicone. As presented in Figure 3, the concentration of CSA-131 in solution after VP incubation decreased by $21 \%$. Additionally, after placing VPs infused with CSA-131 into a ceragenin-free alcohol solution, the concentration of CSA-131 in this solution slowly increased (Figure 3).

In vitro tests revealed that the fungal biofilm formation of clinical isolates of C. albicans was significantly inhibited on the surface of VP that were previously incubated in CSA-131 and alcohol solution versus the control groups. The study has shown that other ceragenins, such as CSA-13 or CSA-44, embedded into the silicon of VP also had fungal biofilm formation inhibition properties (Figure 4) (Table 2). 
Table 1. Comparative antimicrobial activities of tested agents in vitro, against four most common species of yeast isolated from damaged voice prostheses.

\begin{tabular}{|c|c|c|c|c|c|c|c|c|c|}
\hline \multirow{2}{*}{ Agent } & \multicolumn{3}{|c|}{ MIC ( $\mu \mathrm{g} / \mathrm{mL})$} & \multicolumn{3}{|c|}{$\operatorname{MFC}(\mu \mathrm{g} / \mathrm{mL})$} & \multicolumn{3}{|c|}{ MBIC $(\mu \mathrm{g} / \mathrm{mL})$} \\
\hline & Range & $50 \%$ & $90 \%$ & Range & $50 \%$ & $90 \%$ & Range & $50 \%$ & $90 \%$ \\
\hline & \multicolumn{9}{|c|}{ Candida albicans $(\mathrm{n}=14)$} \\
\hline Amphotericin B & $0.5-512$ & 0.5 & 1 & $0.5-512$ & 0.5 & 1 & $0.5-512$ & 1 & 32 \\
\hline Fluconazole & $0.5-512$ & 16 & 512 & $1-512$ & 128 & 512 & $2-512$ & 128 & 512 \\
\hline Omiganan & $32-512$ & 128 & 256 & $64-512$ & 128 & 256 & $64-512$ & 128 & 256 \\
\hline LL-37 & $16-512$ & 512 & 512 & $64-512$ & 512 & 512 & $64-512$ & 512 & 512 \\
\hline CSA-13 & $0.5-8$ & 2 & 8 & $1-8$ & 4 & 8 & $2-16$ & 4 & 8 \\
\hline CSA-131 & $0.5-2$ & 0.5 & 2 & $0.5-2$ & 0.5 & 2 & $0.5-2$ & 1 & 2 \\
\hline CSA-44 & $1-8$ & 4 & 8 & $1-8$ & 4 & 8 & $1-8$ & 4 & 8 \\
\hline \multirow[t]{2}{*}{ CSA-138 } & $0.5-4$ & 1 & 4 & $0.5-4$ & 1 & 4 & $0.5-8$ & 1 & 4 \\
\hline & \multicolumn{9}{|c|}{ Candida krusei $(\mathrm{n}=15)$ * } \\
\hline Amphotericin B & $0.5-128$ & 1 & 4 & $0.5-256$ & 2 & 8 & $0.5-256$ & 2 & 4 \\
\hline Omiganan & $16-256$ & 64 & 128 & $32-512$ & 64 & 128 & $32-256$ & 128 & 256 \\
\hline LL-37 & $16-512$ & 512 & 512 & $16-512$ & 512 & 512 & $16-512$ & 512 & 512 \\
\hline CSA-13 & $0.5-2$ & 2 & 2 & $0.5-2$ & 2 & 2 & $0.5-8$ & 2 & 4 \\
\hline CSA-131 & 0.5 & 0.5 & 0.5 & 0.5 & 0.5 & 0.5 & $0.5-1$ & 0.5 & 1 \\
\hline CSA- 44 & $0.5-4$ & 1 & 2 & $0.5-4$ & 1 & 2 & $0.5-4$ & 1 & 4 \\
\hline \multirow[t]{2}{*}{ CSA-138 } & $0.5-4$ & 0.5 & 1 & $0.5-4$ & 0.5 & 2 & $0.5-4$ & 1 & 2 \\
\hline & \multicolumn{9}{|c|}{ Candida tropicalis $(\mathrm{n}=12)$} \\
\hline Amphotericin B & $0.5-8$ & 1 & 4 & $0.5-16$ & 2 & 8 & $0.5-16$ & 2 & 4 \\
\hline Fluconazole & $1-512$ & 2 & 32 & $2-512$ & 4 & 128 & $2-512$ & 4 & 128 \\
\hline Omiganan & $16-128$ & 32 & 128 & $16-256$ & 64 & 128 & $32-256$ & 64 & 128 \\
\hline LL-37 & $128-512$ & 512 & 512 & $128-512$ & 512 & 512 & 512 & 512 & 512 \\
\hline CSA-13 & $0.5-2$ & 1 & 2 & $0.5-4$ & 1 & 4 & $0.5-4$ & 1 & 4 \\
\hline CSA-131 & $0.5-1$ & 0.5 & 1 & $0.5-1$ & 0.5 & 1 & $0.5-2$ & 0.5 & 1 \\
\hline CSA-44 & $0.5-2$ & 1 & 2 & $0.5-4$ & 1 & 2 & $1-2$ & 1 & 2 \\
\hline \multirow[t]{2}{*}{ CSA-138 } & $0.5-4$ & 0.5 & 2 & $0.5-4$ & 1 & 2 & $0.5-4$ & 1 & 2 \\
\hline & \multicolumn{9}{|c|}{ Candida glabrata $(\mathrm{n}=13)$} \\
\hline Amphotericin B & $0.5-16$ & 1 & 4 & $0.5-16$ & 2 & 4 & $0.5-128$ & 2 & 16 \\
\hline Fluconazole & $2-512$ & 128 & 512 & $4-512$ & 256 & 512 & $4-512$ & 512 & 512 \\
\hline Omiganan & $16-512$ & 256 & 512 & $32-512$ & 256 & 512 & $64-512$ & 256 & 512 \\
\hline LL-37 & $16-512$ & 512 & 512 & $64-512$ & 512 & 512 & $64-512$ & 512 & 512 \\
\hline CSA-13 & $0.5-4$ & 2 & 4 & $0.5-4$ & 2 & 4 & $0.5-8$ & 2 & 4 \\
\hline CSA-131 & $0.5-1$ & 0.5 & 0.5 & $0.5-1$ & 0.5 & 0.5 & $0.5-4$ & 1 & 2 \\
\hline CSA- 44 & $0.5-4$ & 1 & 4 & $0.5-4$ & 2 & 4 & $1-8$ & 2 & 4 \\
\hline CSA-138 & $0.5-4$ & 1 & 4 & $0.5-4$ & 1 & 4 & $0.5-4$ & 1 & 4 \\
\hline
\end{tabular}

* Candida krusei exhibits natural resistance to fluconazole. MIC/MFC/MBIC values have not been determined. 
Table 2. Antifungal activity of the tested compounds against clinical isolates of Candida albicans $(n=5)$.

\begin{tabular}{|c|c|c|c|c|c|c|c|c|}
\hline \multirow[b]{2}{*}{ Strain } & Amphotericin B & Fluconazole & Omiganan & LL-37 & CSA-13 & CSA-131 & CSA-44 & CSA-138 \\
\hline & \multicolumn{8}{|c|}{ MIC/MFC/MBI } \\
\hline C. albicans 185 & $256 / 256 / 256$ & $256 />256 />256$ & $128 / 128 / 128$ & $>256 />256 />256$ & $1 / 1 / 4$ & $2 / 2 / 2$ & $4 / 4 / 4$ & $2 / 2 / 2$ \\
\hline C. albicans 177 & $0.5 / 0.5 / 1$ & $>256 />256 />256$ & $64 / 128 / 128$ & $>256 />256 />256$ & $2 / 2 / 2$ & $0.5 / 0.5 / .5$ & $1 / 1 / 1$ & $0.5 / 0.5 / .5$ \\
\hline C. albicans 189 & $0.5 / 0.5 / 0.5$ & $>256 />256 />256$ & $128 / 128 / 128$ & $>256 />256 />256$ & $1 / 2 / 2$ & $0.5 / 0.5 / .5$ & $2 / 2 / 4$ & $1 / 1 / 1$ \\
\hline C. albicans 138 & $>256 />256 />256$ & $>256 />256 />256$ & $>256 />256 />256$ & $>256 />256 />256$ & $4 / 4 / 4$ & $1 / 1 / 1$ & $4 / 4 / 4$ & $1 / 1 / 1$ \\
\hline C. albicans 160 & $1 / 2 / 2$ & $128 />256 />256$ & $32 / 64 / 128$ & $>256 />256 />256$ & $2 / 2 / 8$ & $0.5 / 0.5 / 1$ & $1 / 2 / 2$ & $0.5 / 0.5 / 1$ \\
\hline
\end{tabular}

A)

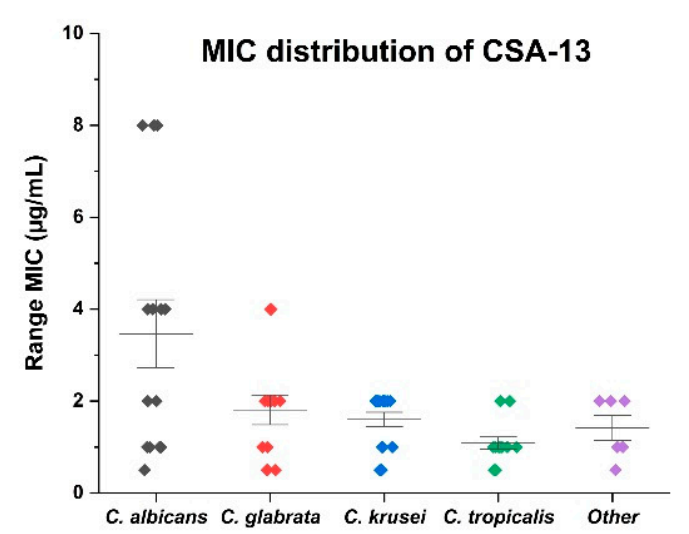

C)

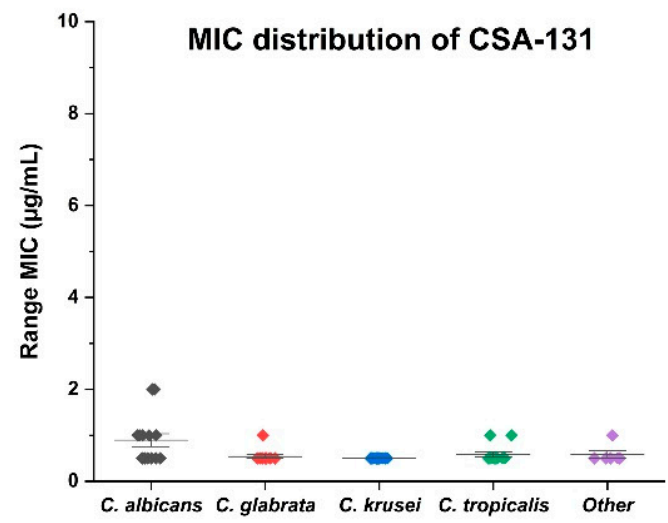

B)

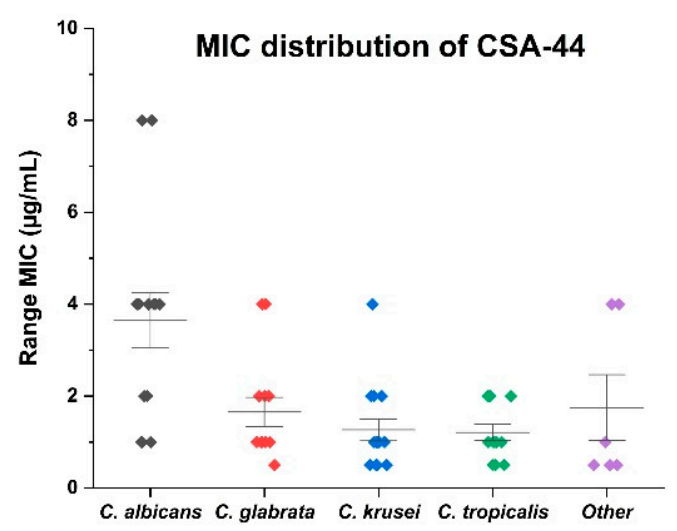

D)

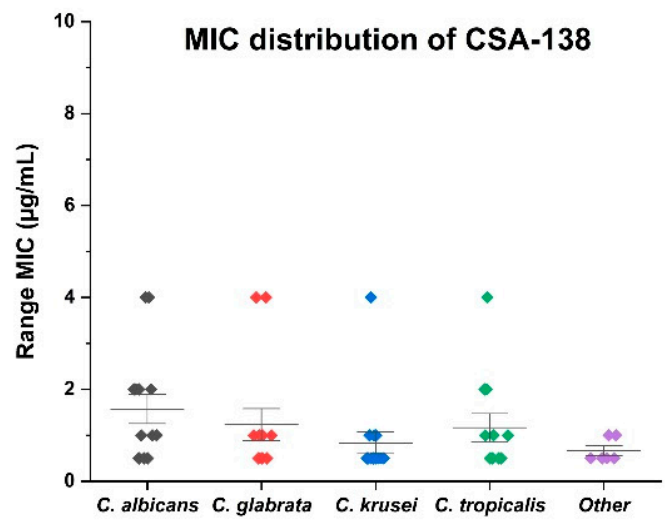

E)

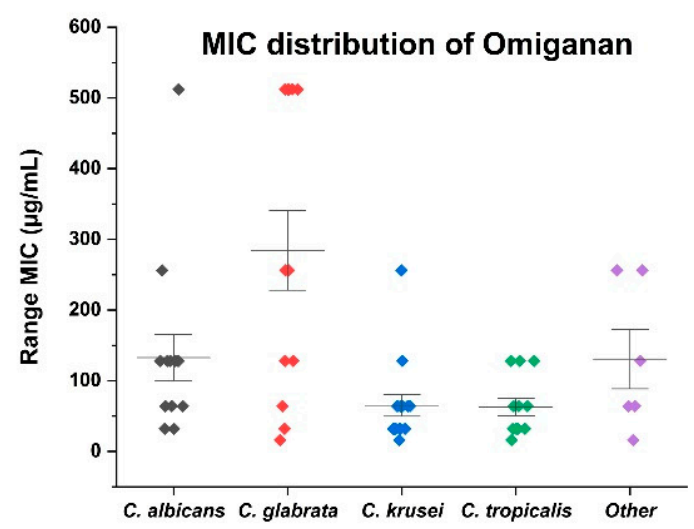

Figure 1. MIC distribution of tested ceragenins (A-D) and omiganan (E) against 60 isolates of Candida species. 
A)

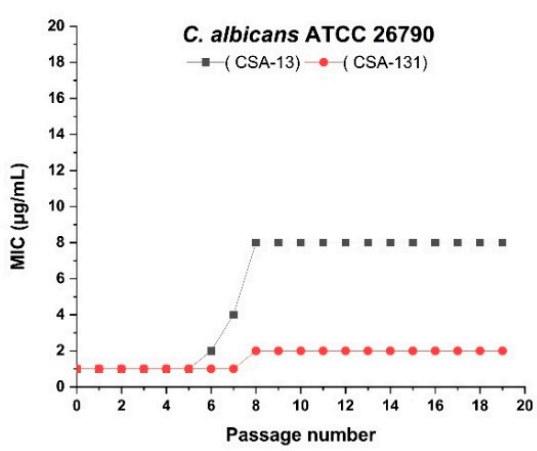

c)

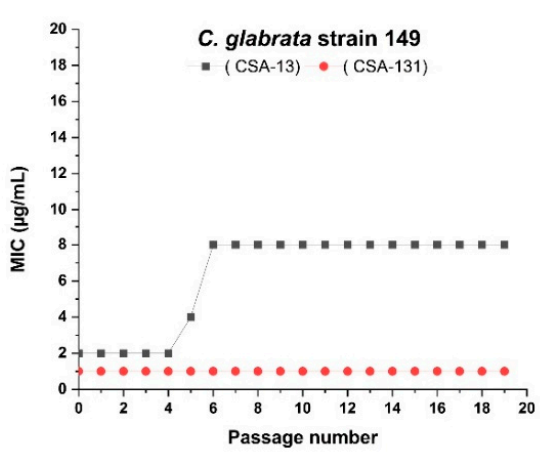

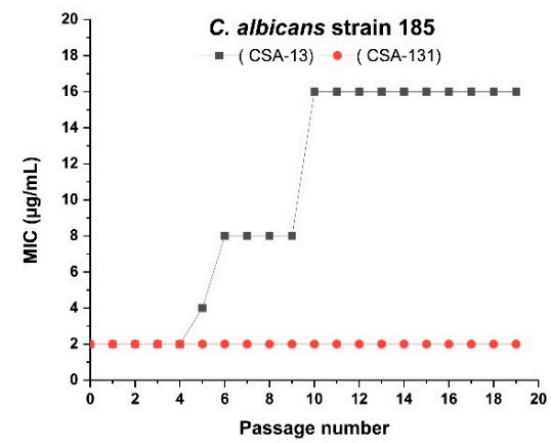

D)

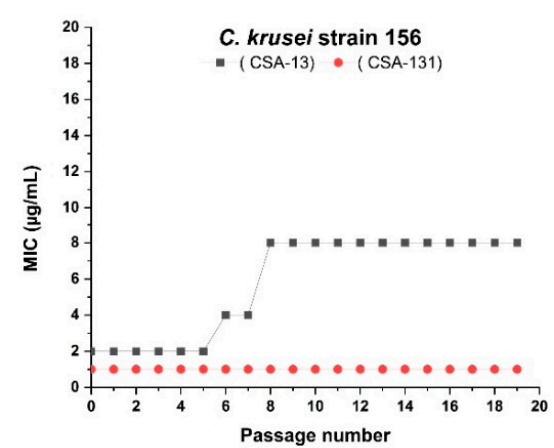

E)

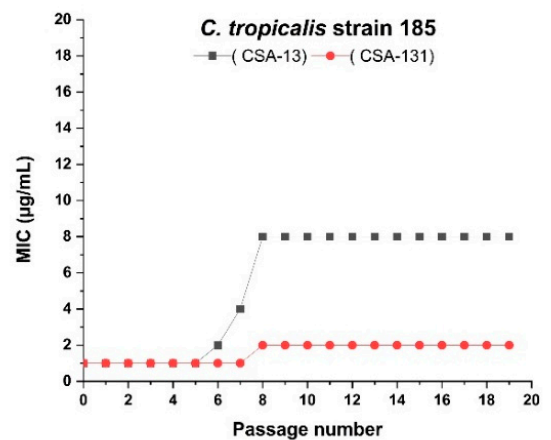

Figure 2. Development of resistance for ceragenins CSA-13 and CSA-131 in selected Candida species (A-E).

A)

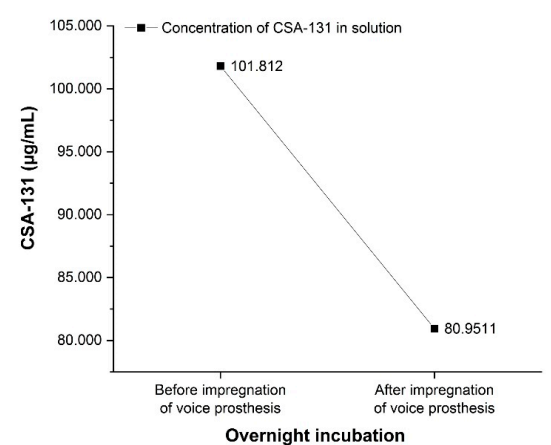

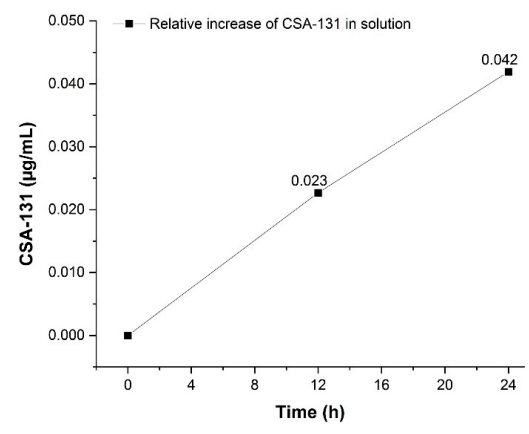

Figure 3. Reduction of CSA-131 concentration in solution as the result of incubation with voice prostheses (A). Relative release of CSA-131 from impregnated voice prostheses into solution over $24 \mathrm{~h}$ of incubation, calculated as the increase in the CSA-131 concentration in relation to its level measured immediately after dipping prostheses in the solution (time 0) (B). 
A)

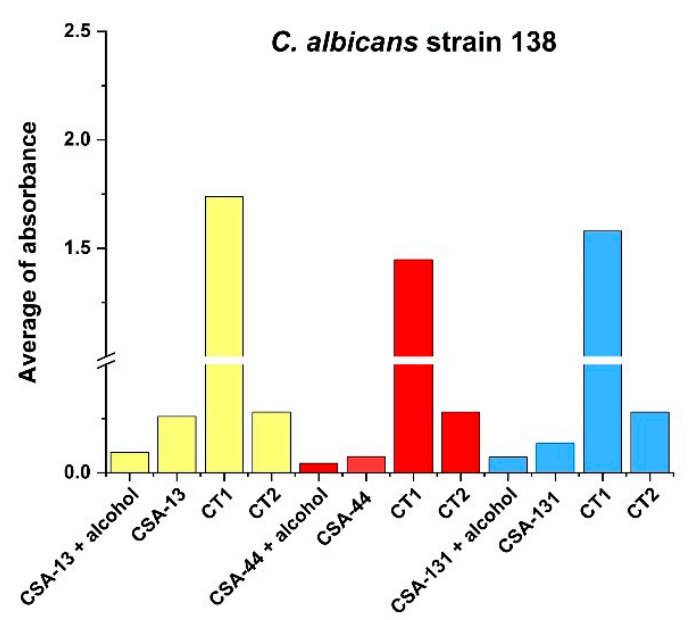

C)

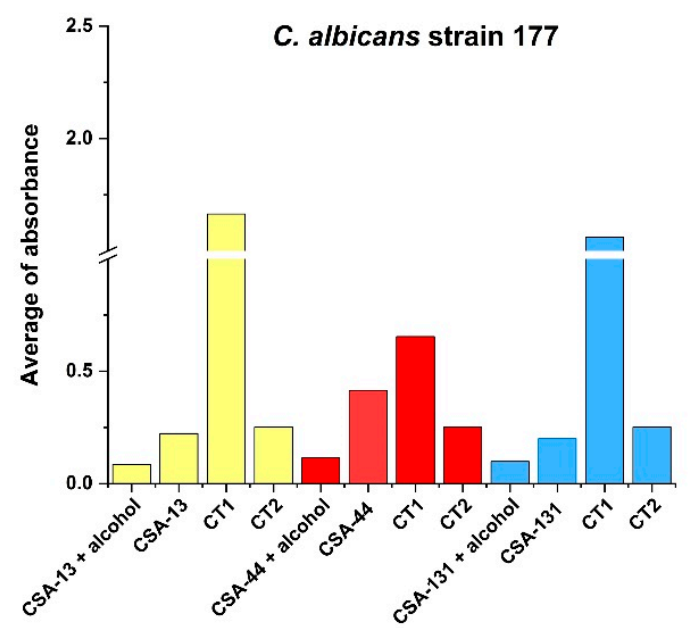

B)

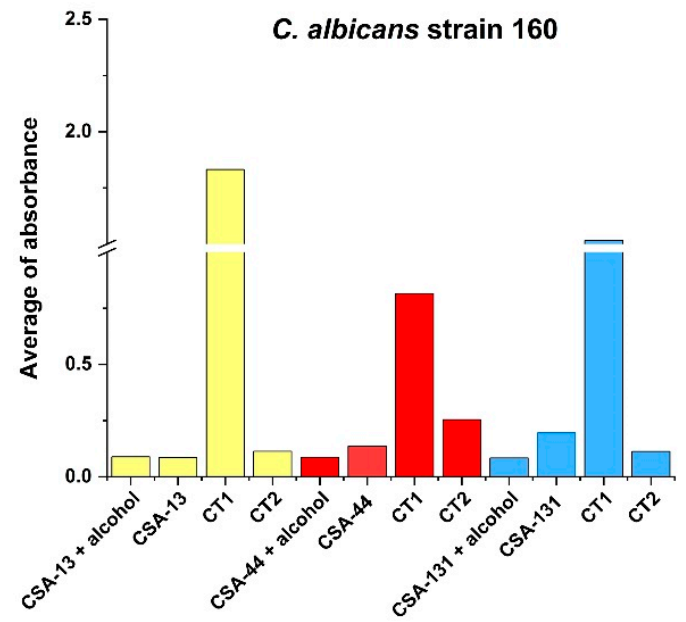

D)

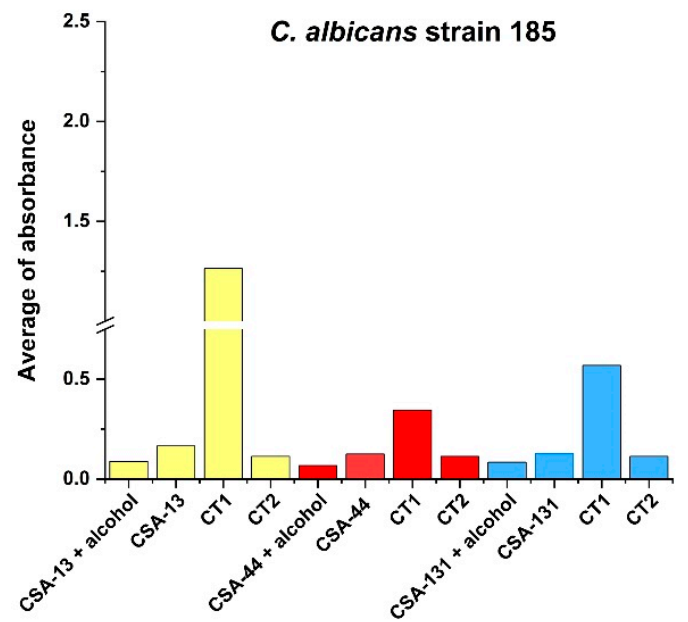

E)

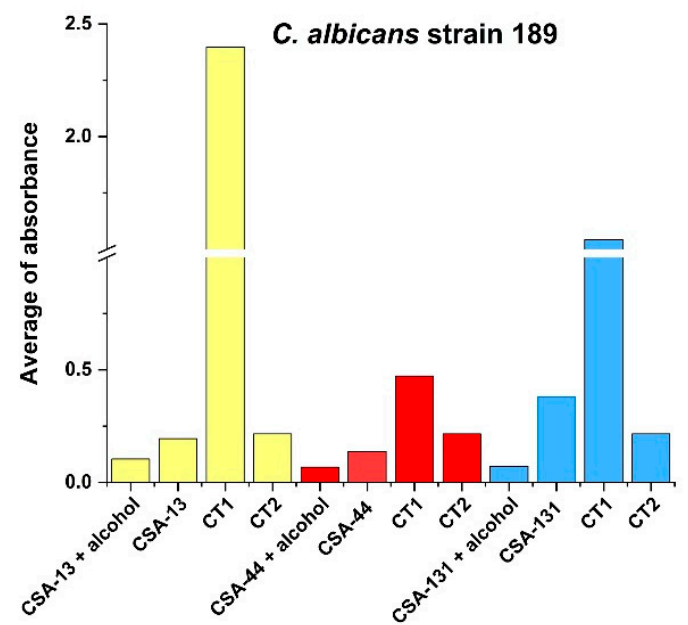

Figure 4. Estimation of biofilm formation by five clinical isolates of C. albicans (A-E) on voice prostheses within $24 \mathrm{~h}$ in RPMI medium initially impregnated by ceragenins: CSA-13 (yellow), CSA-44 (red), and CSA-131 (blue) with alcohol; in the presence of tested CSAs; without ceragenins (CT1) and in alcohol without tested ceragenins (CT2). 


\section{Discussion}

Microbial colonization is one of the most significant disadvantages of indwelling medical devices made of synthetic materials, especially those made of silicone. Colonization presents serious clinical problems for patients with urological catheters, endotracheal tubes, intravascular catheters, orthopedic implants, and optical lens', among others. The initial adherence of Candida spp. to the silicone polymer surface is likely preceded by bacteria, and the synergistic interaction between bacteria and fungi in a mixed biofilm during the surface colonization of medical devices has been described [24]. Colonizing fungi develop a biofilm on the VP surface that is responsible for VP destruction. This could also be a potential cause of local and general infections $[25,26]$. It is worth noting that in the case of VP, microbial colonization is promoted by the properties of the trachea-esophageal fistula environment. VPs are placed in a non-sterile niche, so microorganisms rapidly colonize them, and because of the permanent contact with the exterior environment, they are continuously exposed to additional organisms. Moreover, the microenvironment of the esophagus and trachea (presence of food, moisture, poor drug penetration) promotes biofilm formation. The volume and quality of the biofilm on VPs is different in the esophageal in comparison to the tracheal phalange [7]. This difference is likely caused by the more favorable growing conditions in the esophageal fistula.

Multiple approaches have been evaluated for the inhibition of VP deterioration [27], including the use of probiotics [28]. Notable attempts at inhibiting biofilm growth on VPs were to change the physicochemical properties of the material making the device. However, this approach is complicated by the specific requirements for VPs. They need to maintain their flexibility and compatibility with the host tissue and to be easily inserted or replaced. On the other hand, material that is too flexible can lead to leakage or displacement in the fistula. Changing the material properties to be more resistant to destruction by biofilm growth may result in the loss of these criteria. Currently, only the reduction of silicone surface roughness and the application of anti-adhesive polymers such as 2-(dimethylamino)ethyl methacrylate have been shown to decrease biofilm formation in VPs [29-31]. Another approach is to develop surface coatings of, or impregnate the device with, antimicrobial and/or antiadhesive agents. Recently, results were reported of medical-grade silicone coated with sophorolipids for anti-adhesive and anti-microbial properties [32,33]. Tsikopoulos et al., in a meta-analysis study, have reviewed 33 comparative studies from 1999 to 2019 describing all reported in vitro attempts at inhibition of biofilm formation on silicon rubber VPs [34]. None of these approaches met the criteria of protecting VPs for extended periods without the risk of the emergence of drug resistance.

There are many agents with antimicrobial activities against Candida species. From commonly used antifungals such as nystatin, fluconazole, and amphotericin through endogenic and synthetic antimicrobial peptides to magnetic nanoparticles and photodynamic therapy. All of these have antimicrobial activity against Candida species forming mixed biofilms [2]. Some studies have assessed the antimicrobial activity of ceragenins in some medical device applications. In 2013, one study reported that CSA-138 covalently attached to the hydrogel optic lens-displayed antimicrobial activity and provided extended lifespan to the device [35]. Hashemi et al. have found, in preclinical studies, that a ceragenin-coated endotracheal tube had substantial antimicrobial activities against some Candida species [36]. Other studies showed significant inhibition of biofilm formation on orthopedic implants coated with ceragenins $[37,38]$. However, there are no studies describing the application of ceragenins or nanoparticles in the fight against specific strains of fungal isolates identified on VPs.

In this study, we investigated the fungicidal activity of classic agents compared to ceragenins and their potential application as fungicidal agents against the most common Candida species isolated from biofilm residing on the damaged VPs. Additionally, we investigated the potential of the application of CSA-131 on the surface of the VP biomaterial to prevent its colonization. 
This study has shown that among the ceragenins, CSA-131 is the most effective agent against the four most common Candida species responsible for VP deterioration (Table 1 and Figure 1). Moreover, the development of resistance for CSA-131 by these clinical isolates was not observed during 25 passages. CSA-131 also had the most effective impact on the inhibition of the mass growth of biofilm (Figure 2). We showed that the incubation of VPs in an organic solution of CSA-131 allowed impregnation of the VP with the active agent. Embedded CSA-131 showed significant antimicrobial effects in reducing the biofilm mass of $C$ albicans on the VP surface in vitro. The rate and duration of the CSA-131 released from impregnated VPs were observed for $24 \mathrm{~h}$. The rate was nearly linear over this period, and if this rate remained constant there is the possibility that CSA-131 would remain on the VP for approximately 1.3 years. Because of the short time of measurement, the duration of release was not determined and is the subject of further research and the use of CSA-131 for VP impregnation will require additional study. Nevertheless, a CSA-131-based disinfectant could be developed for regular VP treatment similar to that provided by Provox Flush accessories. It seems that cleaning procedures using CSA-131 could be a more effective substitute for the water recommended for this procedure by the manufacturer.

Our results demonstrate the possibility of developing a method to extend the life of VPs by increasing their resistance to the destructive effects of the most common Candida species with the use of cerulenin CSA-131. With the effective use of this antimicrobial, the replacement procedure could be less frequent, and the potential risk of life-threatening complications would be lower. This fact is significant because total laryngectomy is still the most effective treatment for locally advanced laryngeal cancers [39]. Laryngeal cancer is diagnosed annually in approximately 177,000 patients worldwide $[40,41]$. Most of these are diagnosed at stage $\geq$ III and many of these patients will become VP users.

\section{Materials and Methods}

\subsection{Collection of Candida Strains}

A group of 60 clinical isolates of the most common yeasts from damaged Provox VPs collected during their replacement were used in this study including 14 Candida albicans isolates, 15 Candida krusei isolates, 12 Candida tropicalis isolates, and 13 Candida glabrata isolates, 3 Saccharomyces cerevisiae isolates, 1 Candida parapsilosis isolate, 1 Candida kefyr isolate, and 1 Candida dubliniensis isolate. VPs were removed from laryngectomized patients of the Holy Cross Cancer Center. The replacement procedures were performed by physicians using sterile instruments. Directly after removal, the VPs were placed into sterile containers and immediately transported, at RT (room temperature), to the microbiology laboratory for further analysis. VPs were suspended in $5 \mathrm{~mL}$ of thioglycolate broth and vortexed for 2-3 min. Then, $50 \mu \mathrm{L}$ of the eluted material was seeded onto Sabouraud Agar with antibiotics and Chromogenic Agar (all microbial media were from Thermo Fisher Scientific) for preliminary identification and incubated for $48 \mathrm{~h}$ at $30{ }^{\circ} \mathrm{C}$. After incubation, yeasts were identified using Yeast ID cards (Vitek 2 automated system, bioMerieux). Identified Candida strains were stored in the MAST CRYOBANK system (Mast Diagnostica) at $-70{ }^{\circ} \mathrm{C}$. The stored strains were revived on Sabouraud Agar for further studies.

\subsection{Antifungals, Ceragenins, and Determination of MIC, MFC, and MBIC}

Minimal inhibitory concentrations (MICs) were determined for amphotericin B and fluconazole (purchased from Pol-Aura, Poland), omiganan and LL-37 (purchased from LipoPharm, Gdańsk, Poland), and ceragenins CSA-13, CSA-131, CSA-138, and CSA-44 (synthesized as previously described) [42], using the microdilution method described in the guidelines of the Clinical Laboratory Standards Institute (CLSI) [43]. Antifungal activity of the tested agents against clinical isolates of C. albicans, C. krusei, C. tropicalis, and C. glabrata was determined using pathogen cells in log-phase growth. C. albicans ATCC 26790 and $f$ ATCC 6258 were used as reference strains. Dilutions of tested compounds were prepared in Mueller-Hinton Broth (Thermo Fisher Scientific, Waltham, MA, USA) in 
concentrations ranging from $512 \mu \mathrm{g} / \mathrm{mL}$ to $0.5 \mu \mathrm{g} / \mathrm{mL}$. MICs were determined visually as the lowest concentration of tested agents that showed no microbial growth after 24-48 $\mathrm{h}$ of incubation. In the next step, minimal fungicidal concentrations (MFCs) of all tested agents against all tested isolates were determined by inoculating the tested samples on Sabouraud dextrose agar plates, followed by incubation at $35^{\circ} \mathrm{C}$ in sealed plastic bags to prevent drying. A growth control culture without antifungals was submitted to the same procedures. MFCs were determined visually as the lowest concentration of tested agents that showed no fungal growth after 24-48 h. Minimum biofilm inhibitory concentration (MBIC) was assessed using an MTT test based on the reduction of tetrazolium salts as previously described [44].

\subsection{Subsequential Passages of Selected Candida Strains and the Assessment of Their Susceptibility to Ceragenin}

The in vitro method of serial passage was used to evaluate the probability of developing resistance to ceragenin CSA-13 and CSA-131 in selected Candida species from all the study groups [45]. Before starting this study, the MIC values for each studied species were assessed. For this experiment, the isolate from each studied Candida strain with the highest value of MIC was selected. The C. albicans ATCC 26790 strain was used as a reference. Serial passaging was performed using Sabouraud dextrose agar plates incubated at $35^{\circ} \mathrm{C}$ with the concentration of tested ceragenins just below the MIC value. After an 18-24 h incubation period, cells growing in the highest concentration on the antimicrobial from the previous passage were once again harvested and assayed for the MIC. The process was repeated 25 times.

\subsection{Voice Prosthesis Incubation in Organic Solution of Ceragenin}

The ability of ceragenins to impregnate vocal prostheses was examined after the immersion of small prosthesis fragments $(3 \times 3 \mathrm{~mm})$ in a $10 \%$ solution of CSA-131, CSA-13, and CSA-44 in isopropyl alcohol, followed by incubation at $37{ }^{\circ} \mathrm{C}$ overnight (the CSAimpregnated group). Next, the solution was removed by pipetting and samples were placed into a vacuum chamber at 50 mbar for $4 \mathrm{~h}$ at room temperature to completely evaporate the remaining alcohol. At the same time, another set of the prosthesis fragments was incubated with isopropyl alcohol only and subsequently subjected to the same drying procedure (the alcohol-impregnated group), serving as the control group. All experiments were performed in triplicate.

\subsection{Evaluation of Biofilm Mass}

Five fluconazole-resistant C. albicans clinical isolates (Table 2) were selected to compare biofilm formation on voice prostheses (i) impregnated with a $10 \%$ solution of ceragenins in isopropyl alcohol (the CSA-impregnated group), (ii) incubated with isopropyl alcohol only (the alcohol-impregnated group), (iii) non-impregnated but treated with free ceragenins at a concentration of $2 \times$ MBIC value (the CSA-treated group) (Table 2), and (iv) using non-impregnated and non-ceragenin-treated ones as the control group.

The biofilm cultures were carried out in 96-well microtiter plates in $200 \mu \mathrm{L}$ of RPMI medium (Sigma-Aldrich, Saint Louis, MO, USA) under aerobic conditions for $48 \mathrm{~h}$ at $37^{\circ} \mathrm{C}$. After incubation, the planktonic cells were carefully removed and the biofilms were washed twice with PBS, dried at room temperature, and stained for 15 min using $150 \mu \mathrm{L}$ of $0.1 \%$ crystal violet (Chempur, Poland). Next, the excess of stain was removed, and the biofilms were rinsed with deionized water and the plates left to dry. To solubilize the crystal violet, $100 \mu \mathrm{L}$ of $98 \%$ ethanol was added to each well, and the optical density (OD) was determined at a wavelength of $570 \mathrm{~nm}$ using the Varioscan Lux microplate reader (Thermo Fisher Scientific, Waltham, MA, USA) to estimate the number of bacteria in a biofilm.

\subsection{CSA-131 Quantitation}

CSA-131 concentration was determined using ultra-high performance liquid chromatography (1290 Infinity II, Agilent Technologies) coupled with tandem mass spectrome- 
try (6495 Triple Quad, Agilent Technologies) equipped with iFunnel technology. A sample $(2 \mu \mathrm{L})$ was injected into the chromatographic column (Zorbax RRHD Eclipse Plus C18 $(2.1 \mathrm{~mm} \times 50 \mathrm{~mm}, 1.8 \mu \mathrm{m})$ with a Zorbax Eclipse Plus C18 $(2.1 \mathrm{~mm} \times 5 \mathrm{~mm}, 1.8 \mu \mathrm{m})$ precolumn; both Agilent Technologies) and thermostated at $45^{\circ} \mathrm{C}$. The flow rate was $0.5 \mathrm{~mL} / \mathrm{min}$ with solvent $\mathrm{A}$ (deionized water with $0.1 \%$ formic acid) and solvent $\mathrm{B}$ (acetonitrile with $0.1 \%$ formic acid). The gradient started at $5 \%$ phase $\mathrm{B}$ and rapidly increased to $80 \%$ over $0.4 \mathrm{~min}$, followed by an increase in phase B to $90 \%$ for another $6.6 \mathrm{~min}$, remaining at this solvent ratio for $2 \mathrm{~min}$. Next, the gradient changed to the starting conditions (in $0.01 \mathrm{~min}$ ) and remained at $5 \%$ of phase B for $1.5 \mathrm{~min}$. Analysis was performed in the positive (ESI+) ion mode. The single ion monitoring (SIM) mode was used. The parent ions of the mass 901.6 $(\mathrm{M}+\mathrm{H})$ and $923.7(\mathrm{M}+\mathrm{Na})$ were isolated by the second quadrupole. The capillary voltage was set to $3500 \mathrm{~V}$ and the gas temperature to $280{ }^{\circ} \mathrm{C}$ with a flow rate of $15 \mathrm{~L} / \mathrm{min}$. The nebulizer gas pressure was set at 25 psi and the sheath gas temperature at $350{ }^{\circ} \mathrm{C}$ with a flow rate of $12 \mathrm{~L} / \mathrm{min}$.

CSA-131 was derivatized using acetic anhydride. $100 \mu \mathrm{L}$ of diluted CSA-131 solution was evaporated in the SpeedVac Concentrator (Savant SPD2010, Thermo Fisher Scientific), followed by derivatization with $50 \mu \mathrm{L}$ of acetic anhydride. The samples were vortex-mixed and then incubated for one hour at $45^{\circ} \mathrm{C}$. The reaction mixture was then dried in the SpeedVac Concentrator. The residues were dissolved in a $100 \mu \mathrm{L}$ mixture of water/acetonitrile $1: 1$ with $0.1 \%$ formic acid, and then samples were mixed for $5 \mathrm{~min}$.

\subsection{Statistical Analysis}

The significance of differences was determined using the two-tailed Student's $t$-test. Statistical analyses were performed using Statistica 10 (StatSoft Inc, Tulsa, OK, USA). $p<0.05$ was considered to be statistically significant.

\section{Conclusions}

Of the tested ceragenins, CSA-131 showed the strongest activity against C. albicans, C. krusei, C. tropicalis, and C. glabrata, frequently identified as biofilm-residing fungi in biofilm growing on the surface of VPs. CSA-131 has the potential to reduce C. albicans biofilm mass on voice prostheses in vitro. The impregnation of VPs with CSA-131 might provide a technical approach to develop VP devices that are more resistant to Candida colonization. The development of a CSA-131 solution that could potentially be used as a flushing fluid for the regular maintenance of VP is also strongly supported.

Author Contributions: Conceptualization, R.B., B.D., T.D., J.S.; methodology, T.D., A.G., B.D., R.B.; software, J.S., K.F., P.D.; validation R.B.; formal analysis, R.B.; P.B.S.; investigation, J.S., R.B.; resources, J.S., T.D., S.O., S.G.; data curation, J.S., T.D., B.D., U.W., D.Z., A.G., A.K., M.C. (Mateusz Cieślukand); writing, J.S., T.D., K.F.; writing-review and editing, M.C. (Mateusz Cieślukand), A.K., B.D., R.B., P.B.S.; visualization, M.C. (Michał Ciborowski); K.F., J.S.; supervision, R.B, S.O.; project administration, R.B.; funding acquisition, R.B. All authors have read and agreed to the published version of the manuscript.

Funding: This work was financially supported by grants from the National Science Centre, Poland (UMO-2018/31/B/NZ6/02476 to RB), the Medical University of Bialystok (SUB/1/DN/20/001/1122 to MC), and by a program of the Ministry of Science and Higher Education under the project name “Regional Initiative of Excellence in 2019-2022," project number 024/RID/2018/19 (financing amount: $11,999,000.00$ PLN). Part of the study was conducted with the use of equipment purchased by the Medical University of Białystok as part of the RPOWP 2007-2013 funding, Priority I, Axis 1.1, contract No. UDA- RPPD.01.01.00-20-001/15-00 dated 26.06.2015. The funders had no role in the study design, data collection and analysis, decision to publish, or preparation of the manuscript.

Institutional Review Board Statement: The study was conducted according to the guidelines of the Declaration of Helsinki, and approved by the Ethics Committee of Jan Kochanowski University of Kielce (protocol code 16/2019; date of approval: 05.03.2019).

Informed Consent Statement: Not applicable. 
Data Availability Statement: The data presented in this study are available on request from the corresponding author. The data are not publicly available due to volume.

Acknowledgments: We would like to thank Damian Pawelski MSc, from the Department of Organic Chemistry of the Medical University of Białystok for facilitating this study.

Conflicts of Interest: The authors declare no conflict of interest. The funders had no role in the design of the study; in the collection, analyses, or interpretation of the data; in the writing of the manuscript, or in the decision to publish the results.

\section{References}

1. Souza, F.G.R.; Santos, I.C.; Bergmann, A.; Thuler, L.C.S.; Freitas, A.S.; Freitas, E.Q.; Dias, F.L. Quality of life after total laryngectomy: Impact of different vocal rehabilitation methods in a middle income country. Health Qual. Life Outcomes 2020, 18, 1-12. [CrossRef]

2. Rodrigues, M.E.; Gomes, F.; Rodrigues, C.F. Candida spp./Bacteria Mixed Biofilms. J. Fungi 2019, 6, 5. [CrossRef]

3. Singer, M.I.B.; Blom, E.D. An endoscopic technique for restoration of voice after laryngectomy. Ann. Otol. Rhinol. Laryngol. 1980, 89, 529-533. [CrossRef]

4. Douglas, L.J. Candida biofilms and their role in infection. Trends Microbiol. 2003, 11, 30-36. [CrossRef]

5. Erna, M.; Kojic, R.O.D. Candida Infections of Medical Devices. Clin. Microbiol. Rev. 2004, 17, $255-267$.

6. Galli, J.; Calo, L.; Meucci, D.; Giuliani, M.; Lucidi, D.; Paludetti, G.; Torelli, R.; Sanguinetti, M.; Parrilla, C. Biofilm in voice prosthesis: A prospective cohort study and laboratory tests using sonication and SEM analysis. Clin. Otolaryngol. 2018, 43, 1260-1265. [CrossRef]

7. Spalek, J.; Deptula, P.; Ciesluk, M.; Strzelecka, A.; Lysik, D.; Mystkowska, J.; Daniluk, T.; Krol, G.; Gozdz, S.; Bucki, R.; et al. Biofilm Growth Causes Damage to Silicone Voice Prostheses in Patients after Surgical Treatment of Locally Advanced Laryngeal Cancer. Pathogens 2020, 9, 793. [CrossRef]

8. Talpaert, M.J.; Balfour, A.; Stevens, S.; Baker, M.; Muhlschlegel, F.A.; Gourlay, C.W. Candida biofilm formation on voice prostheses. J. Med. Microbiol. 2015, 28, 199-208. [CrossRef] [PubMed]

9. Laccourreye, O.; Ménard, M.; Crevier-Buchman, L.; Couloigner, V.; Brasnu, D. In Situ Lifetime, Causes for Replacement, and Complications of the ProvoxTM Voice Prosthesis. Laryngoscope 1997, 107, 527-530. [CrossRef] [PubMed]

10. Kress, P.; Schafer, P.; Schwerdtfeger, F.P.; Rosler, S. Are modern voice prostheses better? A lifetime comparison of 749 voice prostheses. Eur. Arch. Otorhinolaryngol. 2014, 271, 133-140. [CrossRef]

11. Spałek, J.; Deptuła, P.; Durnaś, B.; Król, G.; Kaliniak, S.; Bucki, R.; Okła, S. Potential colonization of provox voice prosthesis by Candida spp. with no sign of failure for approximately 10 years exploitation time. Acta Oto-Laryngol. Case Rep. 2021, 6, 60-66. [CrossRef]

12. Ameye, D.; Honraet, K.; Loose, D.; Vermeersch, H.; Nelis, H.; Remon, J.P. Effect of a buccal bioadhesive nystatin tablet on the lifetime of a Provox silicone tracheoesophageal voice prosthesis. Acta Otolaryngol. 2005, 125, 304-306. [CrossRef] [PubMed]

13. Messing, B.P.; Kim, M.; Hirata, R.; Thompson, C.B.; Gebhart, S.; Sugar, E.A.; Saunders, J.M.; Sciubba, J.; Califano, J.A. Evaluation of prophylaxis treatment of Candida in alaryngeal patients with tracheoesophageal voice prostheses. Laryngoscope 2015, 125, 1118-1123. [CrossRef] [PubMed]

14. Chin, J.N.; Jones, R.N.; Sader, H.S.; Savage, P.B.; Rybak, M.J. Potential synergy activity of the novel ceragenin, CSA-13, against clinical isolates of Pseudomonas aeruginosa, including multidrug-resistant P. aeruginosa. J. Antimicrob. Chemother. 2008, 61, 365-370. [CrossRef]

15. Chin, J.N.; Rybak, M.J.; Cheung, C.M.; Savage, P.B. Antimicrobial activities of ceragenins against clinical isolates of resistant Staphylococcus aureus. Antimicrob. Agents Chemother. 2007, 51, 1268-1273. [CrossRef]

16. Leszczyńska, K.; Namiot, D.; Byfield, F.J.; Cruz, K.; Żendzian-Piotrowska, M.; Fein, D.E.; Savage, P.B.; Diamond, S.; McCulloch, C.A.; Janmey, P.A.; et al. Antibacterial activity of the human host defence peptide LL-37 and selected synthetic cationic lipids against bacteria associated with oral and upper respiratory tract infections. J. Antimicrob. Chemother. 2012, 68, 610-618. [CrossRef]

17. Lara, D.; Feng, Y.; Bader, J.; Savage, P.B.; Maldonado, R.A. Anti-trypanosomatid activity of ceragenins. J. Parasitol. 2010, 96, 638-642. [CrossRef]

18. Howell, M.D.; Streib, J.E.; Kim, B.E.; Lesley, L.J.; Dunlap, A.P.; Geng, D.; Feng, Y.; Savage, P.B.; Leung, D.Y. Ceragenins: A class of antiviral compounds to treat orthopox infections. J. Investig. Dermatol. 2009, 129, 2668-2675. [CrossRef]

19. Durnas, B.; Wnorowska, U.; Pogoda, K.; Deptula, P.; Watek, M.; Piktel, E.; Gluszek, S.; Gu, X.; Savage, P.B.; Niemirowicz, K.; et al . Candidacidal Activity of Selected Ceragenins and Human Cathelicidin LL-37 in Experimental Settings Mimicking Infection Sites. PLoS ONE 2016, 11, e0157242. [CrossRef]

20. Durnas, B.; Piktel, E.; Watek, M.; Wollny, T.; Gozdz, S.; Smok-Kalwat, J.; Niemirowicz, K.; Savage, P.B.; Bucki, R. Anaerobic bacteria growth in the presence of cathelicidin LL-37 and selected ceragenins delivered as magnetic nanoparticles cargo. BMC Microbiol. 2017, 17, 167. [CrossRef]

21. Wnorowska, U.; Fiedoruk, K.; Piktel, E.; Prasad, S.V.; Sulik, M.; Janion, M.; Daniluk, T.; Savage, P.B.; Bucki, R. Nanoantibiotics containing membrane-active human cathelicidin LL-37 or synthetic ceragenins attached to the surface of magnetic nanoparticles as novel and innovative therapeutic tools: Current status and potential future applications. J. Nanobiotech. 2020, 18, 3. [CrossRef] [PubMed] 
22. Hacioglu, M.; Haciosmanoglu, E.; Birteksoz-Tan, A.S.; Bozkurt-Guzel, C.; Savage, P.B. Effects of ceragenins and conventional antimicrobials on Candida albicans and Staphylococcus aureus mono and multispecies biofilms. Diagn. Microbiol. Infect. Dis. 2019, 95, 114863. [CrossRef] [PubMed]

23. Bozkurt-Guzel, C.; Hacioglu, M.; Savage, P.B. Investigation of the in vitro antifungal and antibiofilm activities of ceragenins CSA-8, CSA-13, CSA-44, CSA-131, and CSA-138 against Candida species. Diagn. Microbiol. Infect. Dis. 2018, 91, 324-330. [CrossRef] [PubMed]

24. Van Weissenbruch, R.; Albers, L.W.J.; Bouckaert, S.; Nelis, H.J.; Criel, G.; Remon, J.P.; Sulter, A.M. Deterioration of the Provox ${ }^{\mathrm{TM}}$ silicone tracheoesophageal voice prosthesis: Microbial aspects and structural changes. Acta Oto-Laryngol. 1997, 117, 452-458. [CrossRef]

25. Percival, S.L.; Suleman, L.; Vuotto, C.; Donelli, G. Healthcare-associated infections, medical devices and biofilms: Risk, tolerance and control. J. Med. Microbiol. 2015, 64, 323-334. [CrossRef] [PubMed]

26. Leonhard, M.; Schneider-Stickler, B. Voice prostheses, microbial colonization and biofilm formation. Adv. Exp. Med. Biol. 2015, 830, 123-136. [CrossRef]

27. Rodrigues, L.; Banat, I.M.; Teixeira, J.; Oliveira, R. Strategies for the prevention of microbial biofilm formation on silicone rubber voice prostheses. J. Biomed. Mater. Res. 2007, 81, 358-370. [CrossRef] [PubMed]

28. Bourdillon, A.T.; Edwards, H.A. Review of probiotic use in otolaryngology. Am. J. Otolaryngol. 2021, 42, 102883. [CrossRef]

29. Buijssen, K.; Oosterhof, J.J.H.; Basil, L.; Waters, M.; Duits, M.A.; Busscher, H.J.; van der Mei, H.C.; van der Laan, B. Influence of surface roughness on silicone rubber voice prostheses on in vitro biofilm formation and clinical lifetime in laryngectomised patients. Clin. Otolaryngol. 2017, 42, 1235-1240. [CrossRef] [PubMed]

30. De Prijck, K.; De Smet, N.; Coenye, T.; Schacht, E.; Nelis, H.J. Prevention of Candida albicans biofilm formation by covalently bound dimethylaminoethylmethacrylate and polyethylenimine. Mycopathologia 2010, 170, 213-221. [CrossRef]

31. Contreras-García, A.; Bucio, E.; Brackman, G.; Coenye, T.; Concheiro, A.; Alvarez-Lorenzo, C. Biofilm inhibition and drug-eluting properties of novel DMAEMA-modified polyethylene and silicone rubber surfaces. Biofouling 2011, 27, 123-135. [CrossRef]

32. Mendes, R.M.; Francisco, A.P.; Carvalho, F.A.; Dardouri, M.; Costa, B.; Bettencourt, A.F.; Costa, J.; Gonçalves, L.; Costa, F.; Ribeiro, I.A.C. Fighting S. aureus catheter-related infections with sophorolipids: Electing an antiadhesive strategy or a release one? Colloids Surf. B Biointerfaces 2021, 208, 112057. [CrossRef] [PubMed]

33. Ceresa, C.; Fracchia, L.; Williams, M.; Banat, I.M.; Díaz De Rienzo, M.A. The effect of sophorolipids against microbial biofilms on medical-grade silicone. J. Biotechnol. 2020, 309, 34-43. [CrossRef] [PubMed]

34. Tsikopoulos, A.; Petinaki, E.; Festas, C.; Tsikopoulos, K.; Meroni, G.; Drago, L.; Skoulakis, C. In vitro Inhibition of Biofilm Formation on Silicon Rubber Voice Prosthesis: A Systematic Review and Meta-Analysis. ORL J. Otorhinolaryngol. Relat. Spec. 2021, 28, 1-20. [CrossRef] [PubMed]

35. Gu, X.; Jennings, J.D.; Snarr, J.; Chaudhary, V.; Pollard, J.E.; Savage, P.B. Optimization of ceragenins for prevention of bacterial colonization of hydrogel contact lenses. Investig. Ophthalmol. Vis. Sci. 2013, 54, 6217-6223. [CrossRef] [PubMed]

36. Hashemi, M.M.; Rovig, J.; Bateman, J.; Holden, B.S.; Modelzelewski, T.; Gueorguieva, I.; von Dyck, M.; Bracken, R.; Genberg, C.; Deng, S.; et al. Preclinical testing of a broad-spectrum antimicrobial endotracheal tube coated with an innate immune synthetic mimic. J. Antimicrob. Chemother. 2018, 73, 143-150. [CrossRef]

37. Dao, A.; Mills, R.J.; Kamble, S.; Savage, P.B.; Little, D.G.; Schindeler, A. The application of ceragenins to orthopedic surgery and medicine. J. Orthop. Res. 2020, 38, 1883-1894. [CrossRef]

38. Mills, R.J.; Boyling, A.; Cheng, T.L.; Peacock, L.; Savage, P.B.; Tägil, M.; Little, D.G.; Schindeler, A. CSA-90 reduces periprosthetic joint infection in a novel rat model challenged with local and systemic Staphylococcus aureus. J. Orthop. Res. 2020, 38, $2065-2073$. [CrossRef]

39. Bozec, A.; Culié, D.; Poissonnet, G.; Dassonville, O. Current Role of Total Laryngectomy in the Era of Organ Preservation. Cancers 2020, 12, 584. [CrossRef]

40. Ferlay, J.; Colombet, M.; Soerjomataram, I.; Mathers, C.; Parkin, D.M.; Piñeros, M.; Znaor, A.; Bray, F. Estimating the global cancer incidence and mortality in 2018: GLOBOCAN sources and methods. Int. J. Cancer 2019, 144, 1941-1953. [CrossRef]

41. Groome, P.A.; O'Sullivan, B.; Irish, J.C.; Rothwell, D.M.; Schulze, K.; Warde, P.R.; Schneider, K.M.; Mackenzie, R.G.; Hodson, D.I.; Hammond, J.A.; et al. Management and outcome differences in supraglottic cancer between Ontario, Canada, and the Surveillance, Epidemiology, and End Results areas of the United States. J. Clin. Oncol. 2003, 21, 496-505. [CrossRef] [PubMed]

42. Ding, B.; Taotofa, U.; Orsak, T.; Chadwell, M.; Savage, P.B. Synthesis and Characterization of Peptide-Cationic Steroid Antibiotic Conjugates. Org. Lett. 2004, 6, 3433-3436. [CrossRef] [PubMed]

43. CLSI. Reference Method for Broth Dilution Antifungal Susceptibility Testing of Yeasts: Approved Standard, 3rd ed.; CLSI Document M27-A3; Clinical and Laboratory Standards Institute: Wayne, PA, USA, 2008.

44. Meletiadis, J.; Mouton, J.W.; Meis, J.F.; Bouman, B.A.; Donnelly, P.J.; Verweij, P.E. Comparison of spectrophotometric and visual readings of NCCLS method and evaluation of a colorimetric method based on reduction of a soluble tetrazolium salt, 2,3-bis [2-methoxy-4-nitro-5-[(sulfenylamino) carbonyl]-2H-tetrazolium-hydroxide], for antifungal susceptibility testing of Aspergillus species. J. Clin. Microbiol. 2001, 39, 4256-4263. [CrossRef] [PubMed]

45. Pollard, J.E.; Snarr, J.; Chaudhary, V.; Jennings, J.D.; Shaw, H.; Christiansen, B.; Wright, J.; Jia, W.; Bishop, R.E.; Savage, P.B. In vitro evaluation of the potential for resistance development to ceragenin CSA-13. J. Antimicrob. Chemother. 2012, 67, 2665-2672. [CrossRef] [PubMed] 